Resumo

Sim e não. Sim, porque as crianças "adulteceram-se" devido à demanda do adulto de tomá-las como periodo que contém a chave explicativa para o que ele é, fazendo de tudo para que deixem de ser infantis. E não, porque elas resistem. A psicanálise, a partir dos Três Ensaios..., talvez seja um dos poucos campos do conbecimento capaz de admitir o caráter irredutivel da criança: sua sexualidade, seu ponto real. Por isso, nossa civilização insiste em recalcá-la. Até quando a miniaturização das ações dos mais velhos será o espectro que faz os pequenos hesitarem em tornar-se grandes? Descritores: criança; sexualidade; psicanálise.

\section{AS CRIANÇAS DE HOJE SÃO MAIS SABIDAS?}

\author{
Marcelo Ricardo Pereira
}

S

im e não. Sim, porque as crianças "adulteceram-se". Não, porque elas resistem. Ou seja, sim, porque o adulto toma a infância como período que contém a chave explicativa para o que ele é, e faz tudo para que os infantis deixem de sê-lo; não, porque algo da criança não cessa de não se escrever. A psicanálise, a partir dos Três ensaios sobre a teoria da sexualidade - sublinho o último termo -, talvez seja um dos poucos campos do conhecimento, senão o mais expressivo, capaz de admitir o caráter irredutível da criança: seu ponto real. Se ela é falada ao nível significante e fantasiada ao nível imaginário, não há dúvida que sua alteridade é excedida ao nível real. Mas nossa civilização moderna insiste em recalcá-la. A infância que os adultos concebem e inculcam nos pequenos pode mesmo estar longe de si, de seu desejo, de sua sexuação. Até quando acreditaremos na ilusão de que a educação dos pais, a escolar e os 
modos de brincadeiras prescritas e formatadas deverão funcionar como antídoto à caixa de vigilância e punição dos adultos? Até quando tomaremos a infância como "criança esperança", construiremos mais e mais teorias sobre ela, transbordando-nos de nostalgia sobre a aurora de nossas vidas? Até que ponto cuidaremos para que as crianças peçam esmolas nas ruas, prostituam-se, tornem-se "aviõezinhos" do tráfico ou, de mesma ordem, transformem-se em miniexecutivas de agendas lotadas com a escola, o balé, o inglês ou qualquer atividade que possa ser monitorada através de um celular da moda? Enfim, até quando a miniaturização das ações dos mais velhos será o espectro que faz os pequenos hesitarem em tornar-se grandes?

Vejamos. O conceito de infância, curiosamente, não excede a dois pares de século. Ainda que os anos seiscentos o tenham conhecido, apenas no début da modernidade, no século XVIII, ele foi fixado. A infância passou de potência de vida, própria do pensamento pré-moderno, à verdade discursiva de nossos tempos; de uma fecundidade para o trabalho a uma temporalidade do cuidado para se garantir o futuro; de um anonimato histórico à materialidade entusiasmada defendida pelos teóricos e animadores da infância.

Mas ela só ganhou vida quando foi acoplada à crescente necessidade de torná-la letrada, preparada e devidamente escolarizada, bem ao modo dos princípios republicanos. Lembremos que à infância - do latim infans, in fari, quem não fala - ligava-se à ideia de dependência, de inexperiência, de incapacidade para corresponder às demandas sociais mais complexas. $\mathrm{O}$ termo não remetia especificamente à criança pequena, mas aos que não estavam habilitados a falar nos tribunais, ou seja, aos que não podiam se valer de sua palavra para dar testemunho. Eram comum pessoas nessas condições, a exemplo de empregados e escravos, receberem tal denominação. A palavra cbild, do inglês, nos anos seiscentos e parte dos setecentos, era usada para designar adultos que não sabiam ler, isto é, adultos intelectualmente infantis.

De fato, é notável como o conceito de infância foi amalgamado à necessidade de acesso ao mundo letrado, que foi sofisticadamente naturalizado pelas ciências do controle e do exame, a exemplo das psicologias experimental e cognitiva. Elas trataram de racionalizar e reforçar a estratificação do desenvolvimento, para daí estabelecerem seus padrões de normalização. Não hesitemos em supor também que as psicologias do desenvolvimento, sobretudo as que foram tocadas pelo discurso pedagógico e pelas exigências psicodiagnósticas, não se mostraram capazes de se desenredar dos princípios técnico-racionalistas que lhes estavam na origem; a mesma origem de esse frenesi idólatra em relação à biologia ou de se achar que na genética e na 
neurofisiologia encontraremos a chave do cofre.

O problema desse debate não está no que ele descreve, mas no que ele gera. Ao se fixar, por exemplo, o caráter desenvolvimentista da sequência psicogenética piagetiana ou ao se reduzir o sujeito a centros corticais, a giros cerebrais e a sinapses nervosas, torna-se impossível não associar isso ao ideal de racionalização, base fundamental das ciências do controle.

A Psiquiatria, a Psicologia e a Pedagogia, seus métodos e procedimentos diagnósticos, tornaram-se verdadeiramente um dos dispositivos modernos, senão o mais significativo, para que se revelem saberes sobre a criança, sobretudo quando essa criança encarna o risco de colocar sob ameaça o ideal social do adulto letrado. Trata-se de um apelo sistemático à objetividade científica. Cada vez mais torna-se necessário observá-la, medi-la, classificá-la, avaliá-la para explicar o que nela resiste ao ideal do que ela mesma deveria vir a ser. Quando essas ciências passam a focar a infância como objeto de estudo e, nele, as crianças que são produzidas por essa ideia de infância, não há como negar que o que encontramos é uma "pregnância recobridora de sua atualidade" (Vorcaro, 2004, p. 11).

A infância nunca aparece como tal, mas sempre como um devir. Aqui temos uma descontinuidade infanticida. A atualidade da criança sustenta-se numa evanescência que a mantém exposta a uma desmedida

340 Estilos da Clínica, 2011, 16(2), 338-347 
operação de aderência imaginária aos ideais estabelecidos e vigiados pelos observadores da perícia psicopatológica ou pelos observadores das condutas psicopedagógicas.

Não há dúvida de que, ao ganhar consistência histórica, tanto simbólica quanto imaginária, a criança tornou-se visível. Porém, se entendermos Vorcaro (1997), o estudo das condições de visibilidade da infância aponta mesmo é para a virulência de sua opacidade. A tomada da criança pelo discurso conferiu-lhe posição de extremo privilégio, diz a autora, mas trata-se de uma posição que a fixa como aposta no futuro da civilização. Conhecê-la sob todos os ângulos, cuidá-la para que se previnam todos os riscos, superar os efeitos danosos do meio familiar ao seu florescimento saudável, otimizar suas potencialidades são, na verdade, imperativos asseguradores do controle das incertezas do futuro da civilização e, de mesma maneira, são a esperança de garantia da estabilidade da ordem social.

Tomar a infância como futuro, algo que foi por demais naturalizado, é justamente permitir que ela jamais se realize, se efetive ou se insurja como diferença. Tomá-la como devir é manter sob recalque o real inabordável e enigmático que nos ameaça na posição de adultos letrados e normalizados. A infância como devir permite sempre que se resgate o que não foi possível realizar no passado. Ela é projetada como futuro do adul- to ideal ressonante do narcisismo dos pais, dos educadores, dos peritos em geral. O grande sempre acha um jeito de se realizar no pequeno, ao dizer o quanto de si funciona propriamente como modelo para aquele que dele depende. Mas, na verdade, devemos admitir: a infância só existe mesmo enquanto perdida no adulto.

Em nosso passado recente, justamente as marcas que distinguiam o infantil cederam lugar ao acelerado processo de adultização das crianças de hoje. Não raro, tais crianças são convocadas a dominar as novas tecnologias e as novas aparelhagens eletrônicas que as deslocam rapidamente ao mundo dos grandes. A sua precocidade não é só observada, mas desejada. Atualmente não nos assombra testemunhar uma criança de cinco ou seis anos dominar bem o computador, seus jogos, sua linguagem, suas configurações e seu instrumental. Tornou-se comum ver a destreza com a qual uma criança pedinte de tenra idade passa arisca por entre os carros parados nos semáforos das grandes cidades ou como sobem uma nas costas das outras a fazer malabarismos em troca de alguma moeda. Naturalizamos, decerto, a hipererotização dos trajes de uma menina de poucos anos, bem ao sabor dos que vestem uma apresentadora loira $\mathrm{da}$ televisão ou vestem a boneca da moda que mescla ingenuidade e erotismo, contos medievais e sedução imaginária - arquétipo próprio reatualizado por ícones pops como Marilyn Monroe 
ou Madonna. Ou, igualmente, naturalizamos o "estilo" de vida bandida que os meninos de mesma idade procuram ao escolherem suas roupas cada vez mais juvenis ou adultas: calças baixas, repletas de bolsos; tênis sujos e desmazelados; camisetas com dizeres ofensivos à ordem vigente. Tentam, a bem da verdade, imitar a linguagem cultuada e estetizada pela televisão, pelo cinema ou pelo bambambã da escola ou do bairro. Isso tudo - claro - vem recheado de constante reclamação por parte dos pais e educadores da ausência de "boas maneiras", como se eles mesmos não fossem responsáveis por reforçar essa nova moral sexual de conduta pública dos infantes. Relegar tal conduta à "rebeldia" das novas gerações ou ao "fim dos valores", como comumente se diz, é no mínimo obtuso.

Então, estupefatos, perguntamos hoje: nossas crianças são mais sabidas? Elas não são as mesmas de ontem? Em Figuras do infantil, Lajonquière (2010) é lacônico ao dizer que as crianças de hoje são tão diferentes quanto nós o fomos para nossos pais e estes, por sua vez, o foram para nossos avós, assim, sucessivamente. Toda forma histórica é um precipitado de como lidamos com o real: sempre um momento de passagem, nem melhor, nem pior, apenas singular. Eis o ponto de irredutibilidade que a psicanálise não pode deixar de sublinhar: é a sua força.

Em seu notável e não menos polêmico Três ensaios..., no qual um dos ensaios é destinado à sexualidade infantil, Freud (1905/ 1980) chega a afirmar em prefácio que se todos nós pudéssemos aprender através da observação direta das crianças, seus Três ensaios não precisariam ter sido escritos. $\mathrm{O}$ autor, ao longo da obra, e apesar dela, parece se situar no limiar da visibilidade do ser infantil, ao manter o caráter irredutível da criança à sua teorização. É o que podemos traduzir como sua incidência enigmática. $O$ pensamento psicanalítico sobre a sexualidade infantil definitivamente não levou Freud a uma Weltanschaunng (cosmovisão) sobre a infância - ainda que sua vontade iluminista pudesse ter-lhe traído. Mas, ao contrário, o autor adverte-nos o quanto o estudo da criança através do discurso do adulto é fonte de mal-entendidos e equívocos, e que só mediante muitos rodeios pode-se chegar a alguma conclusão parcial, diz Freud.

Enquanto abarca o saber do adulto do que teria sido sua infância, a criança, lembra Vorcaro (2004), é uma formação imaginária inconsciente do adulto psicanalisado que fala sobre o que 
imagina ter sido a sua infância. Junta-se a isso a dimensão simbólica que Freud empresta à criança quando a evoca como representante ideativo ou, dito de outra forma, quando confere a si o estatuto significante, próprio da experiência de linguagem. $\mathrm{O}$ significante crianca deslizou em sua obra, e se multiplicou: fezes, dinheiro, filho, presente e "falo". Esses foram alguns dos significantes localizáveis como equação simbólica ou como representações ideativas. Longe da normalização, tão comum às ciências do controle, isso só fez vir à tona a dimensão inabordável da infância. É preciso uma infinidade de palavras para tentar dar sentido justamente ao que excede ao próprio sentido. A palavra está aquém da coisa. Reduzir a criança a alguma positividade é querer governar a verdade, controlar seus sentidos e racionalidades.

As exigências psicodiagnósticas e as práticas psicopedagógicas, com efeito, demandam essa positividade, querem o saber exato sobre a diferença (e o diferente), para que se tenha o controle preciso sobre suas manifestações e comportamentos. Assim, tem-se a ilusão de que, com essa positividade na mão, psicólogos, pedagogos, cientistas sociais, médicos e outros observadores da infância poderão interpretar e corrigir condutas ou exercer, em termos educativos, a tão almejada ortopedia do cuidado. Mas as consequências disso têm-se mostrado desastrosas para as próprias 
ciências do controle. Embora tais ciências bem-intencionadas - sobretudo com os princípios da racionalidade e do controle da ordem social tragam em suas valises pesquisas interessantes e necessárias, o que elas não deixam de observar é o quanto surge nelas mesmas a exceção, o inesperado, o irredutível ou, no dizer de Freud, o "resíduo incomum" - o "real", no de Lacan (1974/1975). Quanto mais as crianças são sabidas por essas ciências, são faladas, examinadas, checadas, mais insabidos os pequenos se tornam. O diagnóstico nunca é exato, o cuidado nunca é o suficiente, os métodos nunca conseguem codificar tudo. Há sempre alguma neblina: uma criança indócil, um fracasso escolar, um sintoma, uma manifestação sexual a se esclarecer, uma resistência à normalização, enfim, um enunciado que diz ser incerto o futuro da civilização.

Então, temos a exceção como real, assim como temos o ideal como imaginário e a palavra como simbólico. Essas três dimensões teorizadas por Lacan auxiliou a Psicanálise a não se deixar enredar pela objetividade científica e a manter suas verdades sempre "meio-ditas".

A criança real resiste ao ideal e à palavra - resiste às traduções, às normas, ao código, ao futuro. Depreende-se daí um possível estatuto da infância para a Psicanálise. Temos sua dimensão imaginária, constituída pelo olhar dos pais, especialistas e educadores, que reduzem a criança ao mo- 
delo narcísico do que ela deverá se tornar. É uma espécie de jogo de espelho, em que a criança não vê a si mesma ao se projetar na superfície refletora, mas, antes, vê a sua imagem dissimétrica enquanto um adulto padrão, reflexo de seu futuro. Temos também a dimensão simbólica, na qual o enigma da criança é solucionado no nível de uma equação: criança é igual a alguma coisa (criança $=\mathrm{x}$ ). Aqui, ela é tida como um significante que se desloca de um sentido para outro, de acordo com a posição subjetiva em que o adulto a coloca em seu discurso. E, por fim, temos a dimensão real, a dimensão da exceção.

$\mathrm{O}$ real não pode ser reduzido à realidade concreta, mas é justamente o que dessa realidade a atropela. É o acontecimento sem nome, é a coisa sobre a qual não se tem como dizer, ou aquilo que para o sujeito é expulso da realidade pela intervenção da palavra. Aqui, Lacan parece ler bem Freud: o real é sexual. Há sempre algo irredutível da relação sexual que não se deixa nomear. A criança concreta que se manifesta no nosso cotidiano lembra-nos, a contragosto, que somos seres sexuados e, por isso, finitos "castrados", diria Freud. Ela guarda em si esse enigma inabordável, esse obstáculo sexual irredutível, que nos impele à urgência do saber, da produção teórica, sem que jamais alcancemos a sua verdade. $\mathrm{O}$ adulto que teoriza, que narra ou que quer saber sobre sua infância para ao final das contas normalizar e psico-racionali- zar sua sexualidade não admite que algo desse enigma ele jamais poderá escrever A dimensão real está justamente no que a infância o obstaculiza. O que o adulto escreve sobre a criança concreta ou sobre a que narra em suas memórias, perdida para sempre, só faz aparecer o impossível de o todo submeter-se à cifragem ou ao código. Então, se é verdade que a criança resiste ao ideal, por não ser o futuro, mas, sim, uma materialidade presente e viva, $\mathrm{o}$ adulto, que nunca a vê assim, mas, ao contrário, a vê como um enigma, não resiste a outra coisa a não ser ao real, ao resíduo incomum de uma sexualidade que, como nossa diferença mais radical, não se deixa toda escrever.

Ora, se as crianças de hoje são mais sabidas? Sim, pois amiúde elas são imagem e sentido que respondem à demandante voracidade adulta. E, não, pois algo de sua polimorfia sexual é obstáculo irredutível, é real: nada daquilo que diz a infância é verdade, pois somente o é o que, reencontrando-a, a conta, e contando-a, a perde.

Finalizo com Nietzsche: Crueldade sagrada é o título de um de seus emblemáticos aforismos que recupero aqui para, fazendo uso de suas palavras sempre afiadas, concluir estas ideias:

Um homem que trazia nos braços um recémnascido se aproximou de um santo: "Que fazer desta criança? - perguntou ele - É miserável, indesejada e não tem vida bastante 
para morrer". O santo respondeu com voz terrível: "Mata-a e guarda-a três dias e três noites em teus braços para te criar uma memória, assim nunca mais gerarás um filho enquanto não tiver chegado a hora". Ao ouvir estas palavras o homem foi embora desapontado; e muitos criticaram o santo pela crueldade de seu conselho, aos quais respondeu: "Mas não é mais cruel deixá-la viver?” (Nietzsche, 1882/s.d., aforismo 73).

\section{ARE TODAY'S CHILDREN SMARTER?}

\section{Abstract}

Yes and no. Yes because children have "adultified" themselves due to the adult's demand to consider them as the period that holds the key for the adult's own being. And no because the children resist. Psychoanalysis, since the Three Essays..., is perhaps one of the few areas of knowledge which is able to admit the child's irreducible character: its sexuality, its real point. Therefore our civilization insists on repressing it. Until when the actions of older people will be the specter that makes the little ones hesitant to become great?

Index terms: child; sexuality; psychoanalysis.

\section{¿LOS NIÑOS DE HOY SON MÁS SABIDOS?}

\section{RESUMEN}

Síy no. Sí, porque los niños "se adultecieron" debido a la demanda del adulto de tomarlos como un periodo que contiene la clave explicativa para lo que es, haciendo todo lo posible para que dejen de ser infantiles. Y no, porque ellos resisten. El psicoanálisis, desde Tres ensayos ..., es quizás uno de los pocos campos de conocimiento a admitir el carácter irreductible del niño: su sexualidad, su punto real. Por lo tanto, nuestra civilización insiste en reprimirlo. ¿Hasta cuándo la miniaturización de las acciones de los mayores serán el espectro que hace los pequeños vacilaren en tornarse grandes?

Palabras clave: niño; sexualidad; psicoanálisis.

\section{REFEREANCIAS}

Freud, S. (1980). Três ensaios sobre a teoria da sexualidade. In S. Freud, Edição standard brasileira das obras psicológicas completas de Sigmund Frend (J. Salomão, trad., Vol. 7, pp. 121-252). Rio de Janeiro: Imago. (Trabalho original publicado em 1905) 


\section{Dossiê}

Lacan, J. (1974-75). RSI (inédito).

Lajonquière, L. (2010). Figuras do infantil: a psicanálise na vida cotidiana com crianças. Petrópolis, RJ: Vozes.

Nietzsche, F. (s/d.). A gaia ciência. São Paulo: Escala. (Trabalho original publicado em 1882)

Vorcaro, A. (1997). A criança na clínica psicanalitica. Rio de Janeiro: Companhia de Freud.

Vorcaro, A. (2004). O saber "insabido" da criança. In Anais, 4. Colóquio do LEPSI: os adultos, seus saberes e a infância (pp. 11-18), 2002, São Paulo. São Paulo: LEPSI/ FEUSP.

mrp@fae.ufmg.br

Recebido em junbo/2011.

Aceito em agosto/ 2011. 